\title{
OBITUARY: ADVENTURES IN RADIOCARBON AMS WITH DOUG DONAHUE
}

\author{
A J Timothy Jull ${ }^{1,2,3 *}$ (D) $\cdot$ J Warren Beck $^{2,4} \cdot$ George Burr ${ }^{2,5}$ (D) \\ ${ }^{1}$ Department of Geosciences, University of Arizona, Tucson, AZ 85721 USA \\ ${ }^{2}$ University of Arizona AMS Laboratory, Tucson, AZ 85721 USA \\ ${ }^{3}$ Institute for Nuclear Research, 4026 Debrecen, Hungary \\ ${ }^{4}$ Department of Physics, University of Arizona, Tucson, AZ 85721 USA \\ ${ }^{5}$ Department of Geosciences, National Taiwan University, Taipei, Taiwan
}

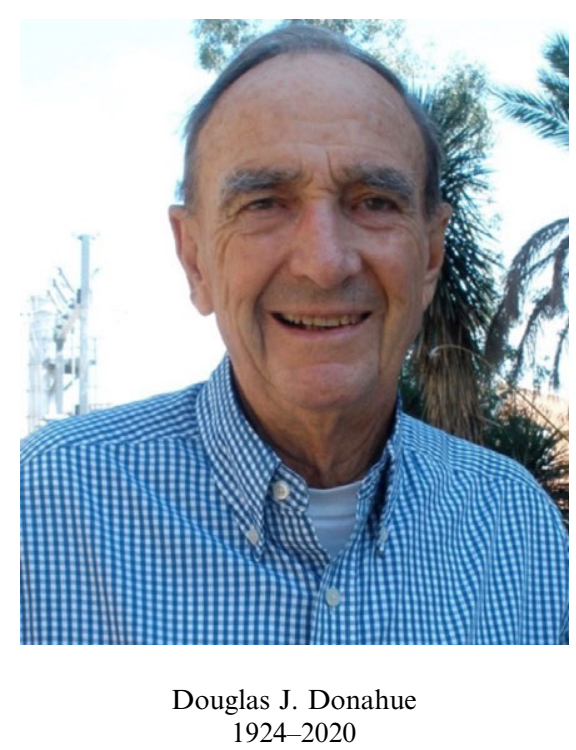

Douglas J. Donahue was one of the pioneers of accelerator mass spectrometry at the University of Arizona. He passed away just shy of his 96th birthday in September 2020, exactly six months after Dee, his beloved wife of 72 years. We all have fond memories of the time we spent working with Doug, and he left his mark on us all. We'd like to share some of those memories, in a slightly scientific context.

Doug was born in 1924, on Douglas St. in Wichita, Kansas, while his parents were on their way to California to begin a new life there. He grew up in Los Angeles, where at age 16 he was one of the first people to drive on the Pasadena Freeway on its opening day in 1940. During World War II, he volunteered for the U.S. Navy, where he commanded a landing craft across the Pacific as part of the planned invasion of Japan in 1945. Its hard to imagine piloting a flat bottom boat with no keel across the vast Pacific, where your ultimate mission would be to ferry hundreds of men to the beaches of Japan in the face of withering gun and cannon fire. Such crafts were notoriously difficult to control and very uncomfortable in rough seas. When asked about the trip, he said it was "memorable." Fortunately for him, the war ended just before the U.S. naval fleet arrived.

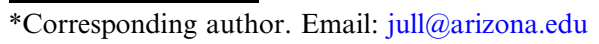


Doug used the GI Bill to get an education at the University of Oregon where he met his future wife, Dee Marie Moore, and married her in 1948. He got his Ph.D. in nuclear physics from the University of Wisconsin, then moved to Hanford, Washington, to work on General Electric nuclear reactors. After a brief stint as assistant professor at the Penn State University Physics department, he was recruited by the University of Arizona Physics Department in Tucson in 1963. Doug first worked there on accelerator-based beam-foil spectroscopy in Professor Stanley Bashkin's research group. The group survived until the mid-1970s, when it suffered the bane of all American scientists, loss of funding from its prime source of support, the National Science Foundation.

Luckily, about this time, a new method of measuring radiocarbon, using accelerator mass spectrometry (AMS) was being developed at the University of Rochester, and by a separate consortium of scientists from McMaster and Simon Fraser Universities. The Arizona physicists learned of a pending request for proposals from the U.S. National Science Foundation for establishing centers for AMS research, and, to cut a long story short, the University of Arizona AMS Laboratory was born, becoming the first NSF-center for AMS radiocarbon research in the United States. The original investigators were Doug and Paul Damon, who had an extensive career in radiocarbon dating to add to Doug's expertise in accelerator physics. They started a long and sometimes acrimonious partnership which softened after Paul retired from the university in 1989. Tim Jull arrived in 1981 with the mission to set up the sample preparation part of the laboratory, and at the same time the late physicist Ted Zabel was hired by Doug to set up the AMS machine: a custom-built 2.5 MV tandem accelerator system developed by Ken Purser was built by General Ionics Corporation. The small-sample capabilities of AMS opened large fields of radiocarbon dating that previously had not been possible, and we were deluged with requests to date everything from bat guano to priceless artifacts. At the time, the Arizona AMS lab was one of only a handful of radiocarbon labs in the world with AMS technology, but Doug was ever willing and ready to help foster new AMS labs. Today there are some 140 AMS machines around the world, not a few of which were founded by scientists who came to Arizona to learn and share AMS techniques.

A high point of these early days of radiocarbon by AMS was the dating of the Shroud of Turin, reputed to be burial cloth of Christ. These measurements continue to generate deep interest and for some believers, even controversy. Doug's involvement with the Shroud began during the 1985 Radiocarbon conference in Trondheim (Norway), where a meeting between all the labs that were interested in dating the Shroud took place. They came up with a document called the "Trondheim Protocol," which sounds like a spy novel, but which proposed there would be 4 AMS and 3 counter labs doing the dating measurements. The Catholic authorities in Turin agreed to take samples of the shroud for dating but reduced the number of laboratories involved to 3 (Arizona, Oxford, and ETH-Zürich). Doug was present when the Shroud was sampled, and on April 21, 1988, the samples were brought to Tucson. By early May, we had an idea of the verdict, although everyone was sworn to secrecy and the labs had all agreed to release the results together, which happened in September 1988. The Shroud was a medieval-age work of art, with all three labs arriving independently at the same conclusion (Damon et al. 1989; Nicolotti 2019). Even so, much interest in the Shroud of Turin continues to this day, especially amongst those wishing to disprove the relatively young radiocarbon age of the Shroud found by AMS dating. Some rather extreme rationales proposed to explain its young age were that neutrons emitted during Christ's resurrection produced excess radiocarbon, making its radiocarbon age "too young" (see for 
example, Phillips 1989), but this idea has no scientific or religious basis. Many people interested in the subject visited or wrote to Doug over the years, some claiming that the radioactive decay equation was wrong, or that the calculations were incorrect. Another claimed there were coatings on the Shroud linen fibers made by bacteria that fixed carbon out of the air. Still another said that exposure to fire and the silver container it was once stored in had changed its isotopic composition. Other wilder conspiratorial theories were also circulated. Unfortunately, "true believers" are not easily convinced by scientific evidence (Nicolotti 2019).

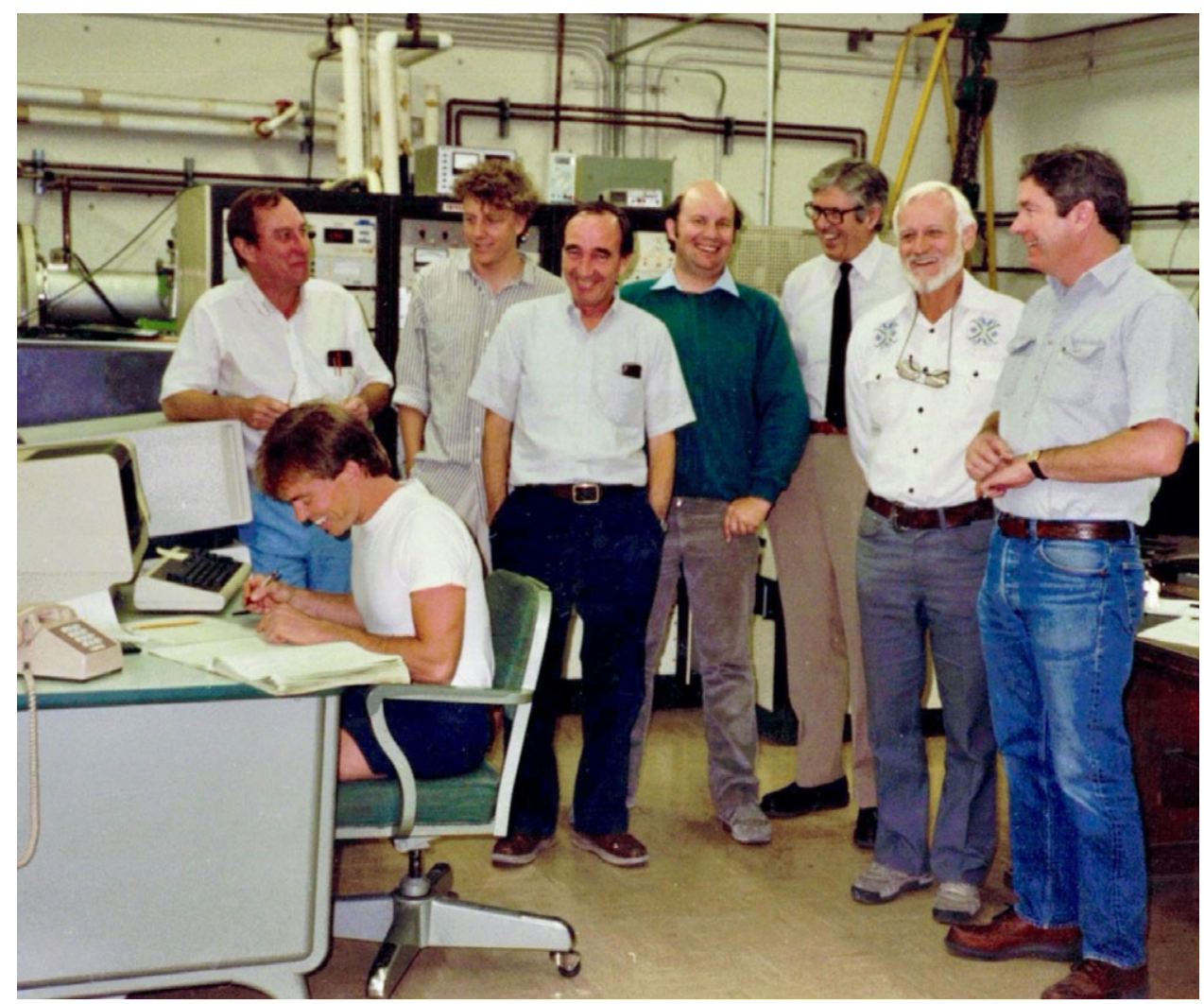

Members of the Tucson AMS group on May 6, 1988, just after the first measurements of the Shroud of Turin: (seated) Brad Gore; (standing, left to right) Larry Toolin, Pat Sercel, Doug Donahue, Tim Jull, Harry Gove, Paul Damon, and Art Hatheway.

Another scientist, Tim Linick, had joined the team in the mid-1980s. However, Tim Linick sadly took his own life in 1989. The death of Tim Linick was hard on the entire lab, but especially on Doug, who remained in his office with the door closed for several days following Linick's death. He struggled with the tragedy, privately agonizing over whether he'd missed signs of depression leading to his suicide, and wondering if he'd pushed Linick too hard. Doug himself was a very hardworking man, who for 31 years usually rode his bicycle to work and packed a bag lunch so he could work from his desk during lunch. He preferred to not waste time dawdling at restaurants, except on occasional Fridays, when he would join members of the lab for a leisurely lunch and lively discussions. Doug led by example and inspired everyone in the lab to work hard. At the same time, he always 
treated us as colleagues not subordinates. He always took a very engaged approach to whatever was happening in the lab. If the AMS machine was not operating correctly, which was not uncommon, he'd expect you to fix it, especially if you had caused the problem. If the AMS broke down just before you happened to have vacation scheduled, and it was your job to fix it, well, you were expected do so before you left. But Doug was usually there working alongside you. In one case, Tim Jull managed to sweep a ${ }^{12} \mathrm{C}$ beam across the detector, destroying it. Doug was rather displeased by this and said little for several days. Then, he did the same thing himself. After that, all was forgiven. Doug always had an open-door policy, and no matter how busy he was, he would take time for you. His chalk board was always filled with scribbled equations and figures that colleagues had drawn there, because he was the go-to guy if you had a problem you couldn't solve or an exciting new idea you wanted to discuss.

Doug was a dedicated family man, with four daughters and a son, in addition to his wife Dee. But he also treated his colleagues like family and would often invite our relatively small group to family events, usually a barbeque, where the cuisine featured what Doug called "burnt chicken." No one ever got salmonella poisoning from undercooked chicken at one of Doug's barbeques. He loved his Arizona home. When one of us remarked that Chicago was the ideal place to pursue a Ph.D. because on a bitter cold winter day, you were happy to stay in your office; Doug countered, saying that Arizona was the ideal place to pursue a Ph.D., because you were always certain that tomorrow would be another perfect day. Doug was a Catholic with deeply held religious beliefs, though you'd never know this unless you brought it up yourself. Taking Christ's philosophy of giving to heart, he was president of the local St. Vincent de Paul center and regularly volunteered at their relief center food shelf, handing out food and other sustenance to the needy. Once, a young colleague from China who was visiting the lab had some serious dental issues, but no dental insurance. He took her to the dentist and had her teeth fixed at his own expense, because that's the kind of man he was.

Doug famously had a cartoon posted on his wall skewering geoscientist lab members' penchant for long trips to collect samples for radiocarbon dating in some unlikely but beautiful corner of the world, where field work just "had" to be done. That cartoon commandeered and parodied a naval slogan: "Become a geoscientist and see the world." That was his way of quietly and humorously criticizing those of us who had a penchant for too much travel. Despite this, Doug made a number of extensive trips himself, across Europe from Norway to France in 1985 , to various conferences, to Xi'an in 1990. This also included two sabbaticals, one in Munich, and the other at Oxford. He used those sabbaticals to foster connections by visiting various AMS labs across Europe. He was a regular at AMS conferences from 1981 to 2002, and a frequent participant of Radiocarbon conferences.

This mix of Doug's personality would sometimes manifest itself at unusual times. Once, a group of us went to an AMS conference in Nagoya (Japan). After that, part of the group decided to spend some extra days in Japan. Doug particularly wanted to visit Hiroshima. We took the bullet train there and stayed overnight at a hotel on the water, which Doug thought would be a great fishing location. The next day, we visited the Hiroshima Peace Memorial Park and Museum in the center of Hiroshima. This was "ground zero" for the first nuclear weapon used against a city. If you have never visited this museum, it is an excellent but shocking display of the horrors of nuclear weapons. It is hard not to be affected by this museum. Doug was deeply moved by this visit and was visibly upset for 
the rest of the day. Later, he shared his feelings of angst that "all those people died" while he had survived. His naval orders near the end of the war had been to sail his landing craft for an expected invasion of Japan. That invasion never happened as a result of these events.

Another aspect of Doug's character was that, perhaps due to his Irish heritage, he had a mischievous sense of humor, and could also be very blunt. Sometimes, he would give amusing advice. In one case, some of the staff were interested in experiments in "cold fusion" which surfaced in about 1985, where physicists from BYU claimed they could start controlled nuclear fusion electrolytically in a test tube containing palladium. This turned out not to be the case, but the press was all over it for some time. We approached Doug about these reports. Doug's response was "wait 30 days." We dutifully waited and returned after 30 days. "It's a fake" was Doug's response. When asked why, he said "they would all be dead from radiation poisoning." He was right, as usual.
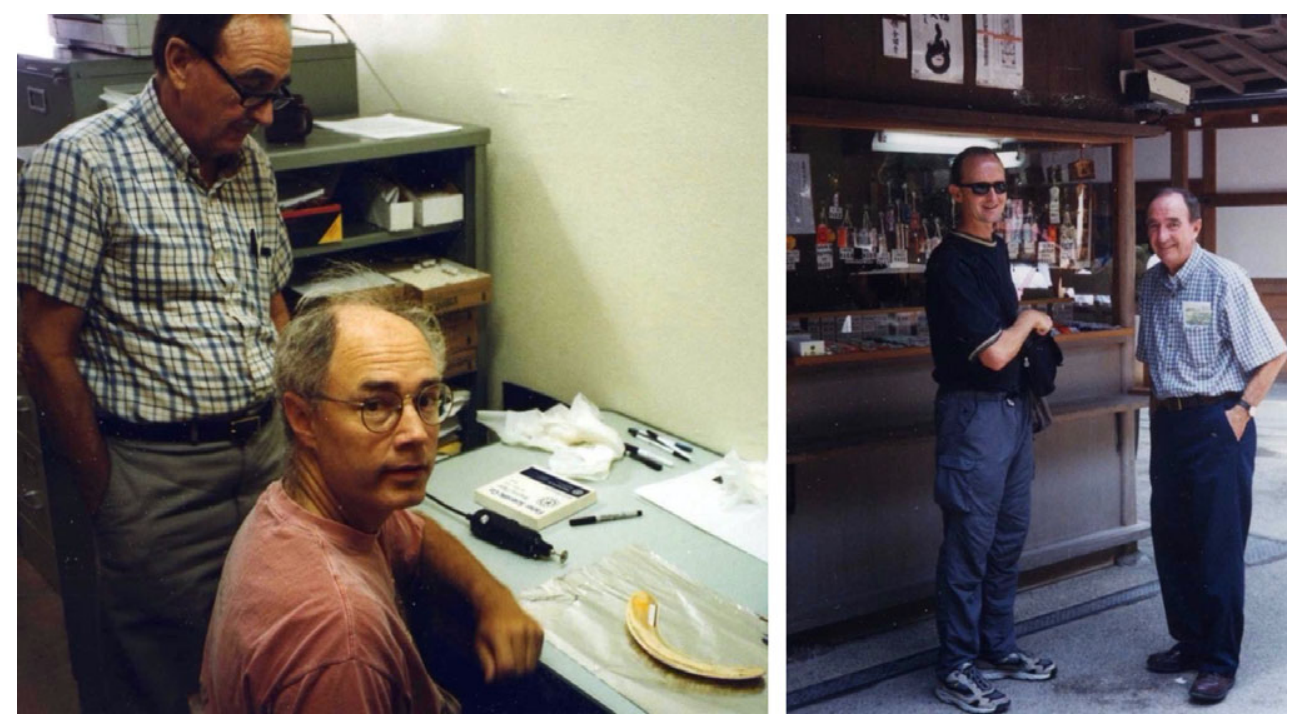

(Left) Doug Donahue and Warren Beck prepare a sample for dating at the University of Arizona; (right) George Burr and Doug Donahue during the 2002 AMS conference in Nagoya, Japan.

Doug was an avid supporter of the Arizona Wildcats basketball team and had some coveted season tickets at McKale Center. He rigorously attended the Arizona Opera in Tucson. He also loved fishing, though opportunities for it were limited in Arizona, which has been described as the "All beach, no ocean" state. Sometimes Doug would rent a boat in San Diego for deep-sea fishing in his earlier days. After his retirement in 2000, he would return to the lab at least once a week, usually on Fridays, in order to go out to lunch and "catch up" with the goings-on at the lab and science in general. We had extensive scientific and sometimes political debates that could go on for some considerable time.

Doug had an extensive scientific career, but it was always clear to us that his family came first. He made us feel like family too. To those of us that experienced this, we feel blessed, and miss him to this day. 


\section{REFERENCES}

Damon PE et al. 1989. Radiocarbon dating of the Shroud of Turin. Nature 337:611-615.

Nicolotti A. 2019. The Shroud of Turin: The history and legends of the world's most famous relic. Waco, TX: Baylor University Press.

Phillips TJ. 1989. Shroud irradiated with neutrons? Nature 337:594. 